\title{
Novel Transdermal Ethosomal Gel Containing Green Tea (Camellia sinensis L. Kuntze) Leaves Extract: Formulation and In vitro Penetration Study
}

\author{
Delly Ramadon, Goldie Aisha Wirarti, Effionora Anwar \\ Laboratory of Pharmaceutics and Pharmaceutical Technology Development, Faculty of Pharmacy, Universitas Indonesia, Depok, 16424, INDONESIA.
}

\begin{abstract}
Background: One of the natural products that have many benefits is green tea (Camellia sinensis L.). It can be used to maintain health because of its high antioxidant activity from epigallocatechin gallate (EGCG). However, EGCG has a low ability to penetrate through the skin due to its hydrophilicity. The aim of this study is to improve the penetration of EGCG through the skin by lipid nanovesicle, namely ethosome. Methods: Ethosomes were made using thin layer hydration method. Ethosomes were formulated with different concentration, equal to $1 \%(F 1), 1.5 \%(F 2)$, and $2 \%(F 3)$ of EGCG from green tea leaves extract. They were characterized, then a chosen formula would be formulated into a gel dosage form (ethosomal gel). A gel without ethosome (non-ethosomal gel) was prepared as a control. Both of them were evaluated their penetration enhancement ability using Franz diffusion cells with the abdomen skin of Sprague-Dawley rats. Results and Discussion: Based on the results, F1 had a spherical shape, Dv90 $129.00 \pm$ $0.00 \mathrm{~nm}$, polydispersity index $0.05 \pm 0.00$, zeta potential at $-62.6 \pm 5.05 \mathrm{mV}$, and the highest entrapment efficiency of $54.39 \pm 0.03 \%$. The cumulative
\end{abstract}

amount of EGCG penetrated from ethosomal and non-ethosmal gel were $1364.28 \pm 56.32 \mu \mathrm{g} / \mathrm{cm}^{2}$ and $490.17 \pm 2.60 \mu \mathrm{g} / \mathrm{cm}^{2}$, respectively $(p<0.05)$. The flux value of ethosomal and non-ethosomal gel were $56.97 \pm 2.06 \mu \mathrm{g} / \mathrm{cm}^{2}$. hour and $31.09 \pm 0.29 \mu \mathrm{g} / \mathrm{cm}^{2}$. hour, respectively. Conclusion: It can be concluded that ethosomal gel can increase the penetration of EGCG from green tea leaves extract.

Key words: EGCG, Epigallocatechin Gallate, Ethosomes, Franz Diffusion Cell, Green Tea Leaves Extract, In vitro Penetration Test.

Correspondence :

Effionora Anwar, Faculty of Pharmacy, Universitas Indonesia, Kampus Baru UI Depok, West Java - 16424, INDONESIA

Phone: +62-21-7270031, 7864049, 78884557

Email: effi.nora@gmail.com

DOI: 10.5530/jyp.2017.9.67

\section{INTRODUCTION}

One of the natural product that has many benefits is green tea leaves. Green tea leaves contain polyphenols from flavonoid groups, which the type is catechin. ${ }^{1}$ Catechin has advantages in the treatment of diseases and prevention of the damaged skin due to UV-B exposure. Moreover, it has anti-inflammatory and antioxidant activity. ${ }^{2}$ The most abundant content of catechin in green tea leaves is epigallocatechin gallate (EGCG). ${ }^{3}$ However, if EGCG is administered orally, it has a low bioavailability due to enzymatic and first metabolism reactions. ${ }^{3} \mathrm{~A}$ study showed that EGCG has low absorption in the gastrointestinal tract (GIT) (less than 5\% absorbed). ${ }^{4}$ In addition, the most important factor that can limit the bioavailability of polyphenol from green tea leaves is an efflux pump mechanism in the GIT by MRP1 and MRP2 proteins. ${ }^{5}$ Other researchers showed that a conjugated cathecin after hepatic metabolism does not have an antioxidant effect. These problems can be overcome by choosing another route of drug administration. It is transdermal drug delivery system. Transdermal drug delivery system is a drug delivery through the skin into the systemic circulation. ${ }^{6}$ This route can avoid GIT problem, first-pass metabolism, and fluctuations of drug levels in the blood. Additionally, the transdermal administration is non-invasive and can be applied easily. ${ }^{7}$ However, transdermal drug delivery has limitations regarding penetration, especially for drugs that are hydrophilic. ${ }^{6}$ A strategy to enhance drug penetration to the skin is by making nanovesicle, namely ethosome. Ethosome is a lipid-based nanovesicle that is formulated of phospholipids, a high concentration of alcohols (20-45\%), and water. It has a better ability to increase drug penetration than conventional liposomes. ${ }^{8-10}$ This ability is due to the presence of high concentration of ethanol that can make the ethosome more deformable and elastic than a conventional liposome. Also, the ethanol can be a penetration enhancer. ${ }^{10,11}$ Ethosome is a non-invasive vehicle, so it is safe to use it on the skin. ${ }^{8,9}$ Ethosome can be formulated into a semi-solid dosage form, for instance, gel dosage forms. The water content in the gel has a function to moisturize the skin and is comfortable to be used. ${ }^{12}$

As a hydrophilic compound ( $\log P=0.48)$, EGCG has a problem to penetrate through the skin. ${ }^{3}$ Entrapping EGCG in the vesicles will increase its penetration through the skin and its stability from oxidation reaction. Thus, formulating green tea leaves into a lipid-based nanovesicle is one of the best ways to increase its penetration.

In this study, ethosomes of green tea leaves extract (Camellia sinensis L. Kuntze) were formulated, then a chosen formula was incorporated into a gel dosage form. In vitro penetration test was performed using Franz diffusion cells with female Sprague-Dawley rats skin as a membrane. In comparison, the control gel formulation of green tea leaves extract was made. Furthermore, the EGCG chemical analysis was performed by using a TLC-densitometry method.

\section{MATERIALS AND METHODS}

\section{MATERIALS}

Green tea leaves extract (Camellia sinensis L. Kuntze) (Andy Biotech Co. Ltd., China), EGCG standard (Sigma-Aldrich, Singapore), Lipoid P 30 with purity of $97 \%$ phospholipids containing 30\% phosphatidylcholine (kindly provided by Lipoid GmbH, Germany), solvents and other chemical reagents are analytical grade. 


\section{EGCG Assay in Green Tea Leaves Extract}

A calibration curve was made with a standard solution of EGCG, and the sample solution concentration was $1000.0 \mu \mathrm{g} / \mathrm{mL}$. The solution was then spotted on a silica gel plate and eluted using dichloromethane-acetoneformic acid (8:7:1) as the eluent. The plates were then analyzed by TLC scanner at a wavelength of $275 \mathrm{~nm}$.

\section{Antioxidant Activity Test of Green Tea Leaves Extract}

The positive reference solution of ascorbic acid and green tea leaves extract solution were made in different concentration. DPPH $100 \mu \mathrm{g} / \mathrm{mL}$ $(1.0 \mathrm{~mL})$ and methanol $(2.0 \mathrm{~mL})$ were added into $1.0 \mathrm{~mL}$ of each sample solution. The blank solution was made. The mixture was shaken for a few seconds, then incubated at a temperature of $37^{\circ} \mathrm{C}$ for $15 \mathrm{~min}$. The antioxidant activity was determined by measuring the absorbance of each sample by UV-Vis spectrophotometer with an optimum wavelength of $521 \mathrm{~nm}$.

\section{Ethosome Formulation}

Ethosome formulations can be seen in Table 1. Ethosome was prepared using mechanical dispersion method. Firstly, Lipoid P 30 was diluted with dichloromethane. Then the dissolved phospholipid was poured into the round-bottom flask. Dichloromethane in the flask was then evaporated using rotary vacuum evaporator at a temperature of $37 \pm 2^{\circ} \mathrm{C}$. Evaporation was done to form a thin film on a round bottom flask. Nitrogen gas flowed into the thin layer, and it is stored in the refrigerator up to $24 \mathrm{sh}$. The thin layer then hydrated with a hydroalcoholic solution containing green tea leaves extract at $40^{\circ} \mathrm{C}$. Once the ethosomal suspension was formed, ultrasonication was done for $2 \mathrm{~min}$.

\section{Ethosome Characterization}

\section{Morphology}

Ethosomes morphology was analyzed by transmission electron microscope (TEM, JEOL JEM 1400). Samples were shed on a carbon-coated copper grid, the droplet then dried at room temperature and colored using phosphotungstic acid solution. After drying, they were viewed under a microscope at 80,000 magnification and the acceleration voltage of $100 \mathrm{kV}$.

\section{Particle Size Distribution, Polydispersity Index, and Zeta potential}

Particle size distribution and zeta potential of ethosome formulas were measured by Dynamic light scattering (DLS) particle size analyzer with a computerized system (Malvern, Zetasizer). Zeta potential measurements were also performed. Each measurement was performed three times.

\section{The Entrapment Efficiency}

The ethosome suspension was taken $1.0 \mathrm{~mL}$, then centrifuged at $13000 \mathrm{rpm}$ for two times of $30 \mathrm{~min}$. The supernatant was discarded, and the precipitate was collected and extracted with chloroform and ethanol. The solution was then spotted on a silica gel plate and eluted. The plates were then analyzed by TLC scanner. Entrapment efficiency was calculated by the formula:

$$
\% \mathrm{EE}=\frac{\text { ECGG concentration measured }}{\text { Total EGCG in the suspension }} \square 100 \%
$$

\section{Gel Preparation}

Carbomer was dispersed in demineralized water for $24 \mathrm{~h}$. The dispersed carbomer was then homogenized. Triethanolamine was then added into the dispersion. Then the mixture was homogenized to obtain a gel base. Propylene glycol was added to the gel base, then was homogenized. Once the gel was formed, ethosomal green tea leaves extract was added into the basis for ethosomal gel formula (EG), and the green tea extract was dispersed for not-ethosomal gel (NEG). Both gels were then homogenized for $15 \mathrm{~min}$. Both of gel formulations as can be seen in Table 2.

\section{Physicochemical Evaluation of Gel Dosage Forms}

Physicochemical evaluations of gel, including organoleptic test (color, odor, syneresis), homogeneity, $\mathrm{pH}$, viscosity and rheology properties, were conducted.

Table 1: Ethosome formulas

\begin{tabular}{cccc}
\hline Materials & \multicolumn{3}{c}{ Concentration (\%) } \\
\cline { 2 - 4 } & F1 & F2 & F3 \\
\hline Green tea extract & Equal to EGCG 1 & Equal to EGCG 1.5 & Equal to EGCG 2 \\
Lipoid P 30 & 4 & 4 & 4 \\
Ethanol 95\% & 20 & 20 & 20 \\
Propylene glycol & 5 & 5 & 5 \\
Phosphate buffer pH 5.5 & ad 100 & ad 100 & ad 100 \\
\hline
\end{tabular}

Note: (F1) Ethosome formula 1, (F2) Ethosome formula 2 and (F3) Ethosome formula 3

Table 2: Gel formulation

\begin{tabular}{ccc}
\hline Materials & \multicolumn{2}{c}{ Concentration \% $(w / w)$} \\
\cline { 2 - 3 } & EG & NEG \\
\hline Carbomer & 1 & 1 \\
Triethanolamine & 0.6 & 0.6 \\
Propylene glycol & 12.5 & 12.5 \\
Ethosomal green tea leaves extract & Equal to EGCG 0.5 & - \\
Green tea extract & - & Equal to EGCG 0.5 \\
Demineralized water & Ad 100 & Ad 100 \\
\hline
\end{tabular}

Note: (EG) Ethosomal gel and (NEG) Non-ethosomal gel 


\section{Gel Stability Test}

Gel stability test was performed by storing the gel at low $\left(4 \pm 2^{\circ} \mathrm{C}\right)$, room $\left(25 \pm 2^{\circ} \mathrm{C}\right)$, and high $\left(40 \pm 2^{\circ} \mathrm{C}\right)$ temperature. During 8-weeks, organoleptic, homogeneity, and $\mathrm{pH}$ were checked properly. Viscosity and rheology property were seen in the storage room temperature after 8 weeks.

\section{In vitro Penetration Test}

The abdomen skin of female Sprague-Dawley rats aged 2-3 months was used as a membrane in the test. All of the methods for sacrificing the animals have been approved by Ethical Clearance Committee of Cipto Mangunkusumo Hospital, Faculty of Medicine, Universitas Indonesia No. 418/UN.2F1/ETIK/2016. The test was performed by using Franz diffusion cells with a diffusion area of $2.01 \mathrm{~cm}^{2}$ and a $15 \mathrm{ml}$ compartment volume. The receptor compartment was filled with phosphate buffer $\mathrm{pH}$ 5.5 and stirred with a magnetic stirrer at speed of $250 \mathrm{rpm}$. Then, the skin was placed in the donor compartment receptor with the position of the stratum corneum facing upwards. A sample of $1.0 \mathrm{~g}$ was applied to the skin surface. Then, at several time intervals $(2,4,6,8,10,12,14,16,18$, 20 , and $24 \mathrm{~h}$ ) samples $(3.0 \mathrm{~mL})$ was taken from receptor compartment using a syringe and receptor compartment was refilled with the same amount of phosphate buffer $\mathrm{pH}$ 5.5. Next, the sample was inserted into the vial and its concentration measured by TLC-densitometry.

\section{Statistical Analysis}

Statistical analysis of data was performed using GraphPad Prism 6.0 via unpaired t-tests with significance level was set at $\mathrm{P}<0.05$.

\section{RESULTS AND DISCUSSION}

\section{EGCG Assay in Green Tea Leaves Extract}

Eluent dichloromethane-acetone-formic acid (8: 7: 1) produced a peak with Rf of 0.54 . Dichloromethane-acetone-formic acid (8: 7: 1) gave a good Rf value because the solvent mixture could provide a good separation between EGCG and the other components in the extract. This separation produced sharper spots with appropriate terms of $\mathrm{Rf}$; i.e., $\mathrm{Rf}$ is $0.2-0.8{ }^{13}$ Based on the analysis, the area obtained is then calculated into the calibration curve, so the content of EGCG in the extract was $53.20 \pm 0.28 \%$.

\section{Antioxidant Activity Test of Green Tea Leaves Extract}

The smaller the $\mathrm{IC}_{50}$, the higher the antioxidant activity of a compound. The $\mathrm{IC}_{50}$ value of green tea leaves extract was $6.00 \mu \mathrm{g} / \mathrm{mL}$, while the $\mathrm{IC}_{50}$ value of ascorbic acid was $2.37 \mu \mathrm{g} / \mathrm{mL}$. A compound has very strong antioxidant properties when it has a value an $\mathrm{IC}_{50}<10 \mu \mathrm{g} / \mathrm{Ml} .{ }^{14}$ Based on this statement, it can be concluded that both of vitamin $\mathrm{C}$ and the green tea leaves extract has a very strong antioxidant property.

\section{Ethosome Formulation}

The main components of ethosomes were phospholipid and ethanol. Phospholipid that has a similar structure to the lipid bilayer of the skin and the use of ethanol as penetration enhancers were expected to increase the permeability of the membrane of the vesicle to the skin. They also make ethosomes appropriate as transdermal delivery. ${ }^{11}$ Vesicles containing ethanol tends to have a thinner membrane, so the addition of propylene glycol was necessary to hold the leakage of layers as well as penetration enhancers. ${ }^{15}$ The use of phosphate buffer at $\mathrm{pH} 5.5$ has been selected because EGCG is stable at low $\mathrm{pH}(<\mathrm{pH} 6)$. The liquid suspension was then sonicated to decrease the particles size. Sonication performed within two min to prevent the outbreak of the vesicles.

\section{Morphology}

Based on the obtained analysis, all ethosomes prepared had a spherical shape. The results were shown in Figure 1. The resulting shape resembles the shape of ethosomes from the previous study, unilamellar and spherical. ${ }^{16}$

\section{Particle Size Distribution, Polydispersity Index, and Zeta Potential}

All results for particle size, zeta potential, and polydispersity index can be seen in Table 3. Vesicle size that can pass through the deepest skin layer must be smaller than $300 \mathrm{~nm} .{ }^{17}$ It shows that the particle size is an important parameter in transdermal drug delivery. F1 had a particle size distribution between 50.75 to $220.2 \mathrm{~nm}$, with $78.82 \mathrm{~nm}$ as the most dominant particle size. F2 has a particle size distribution between 58.77 to $255 \mathrm{~nm}$, with $91.28 \mathrm{~nm}$ as the most dominant particle size. F3 has a particle size distribution between 122.4 to $295.3 \mathrm{~nm}$, at $190.1 \mathrm{~nm}$ as the most dominant particle size. Based on the value of Dv90 F1 (129.00 \pm $0.00 \mathrm{~nm}), \mathrm{F} 2(155.33 \pm 2.08 \mathrm{~nm})$ and F3 $(232.67 \pm 2.52 \mathrm{~nm})$. They showed that the less active substance that was incorporated into the ethosome

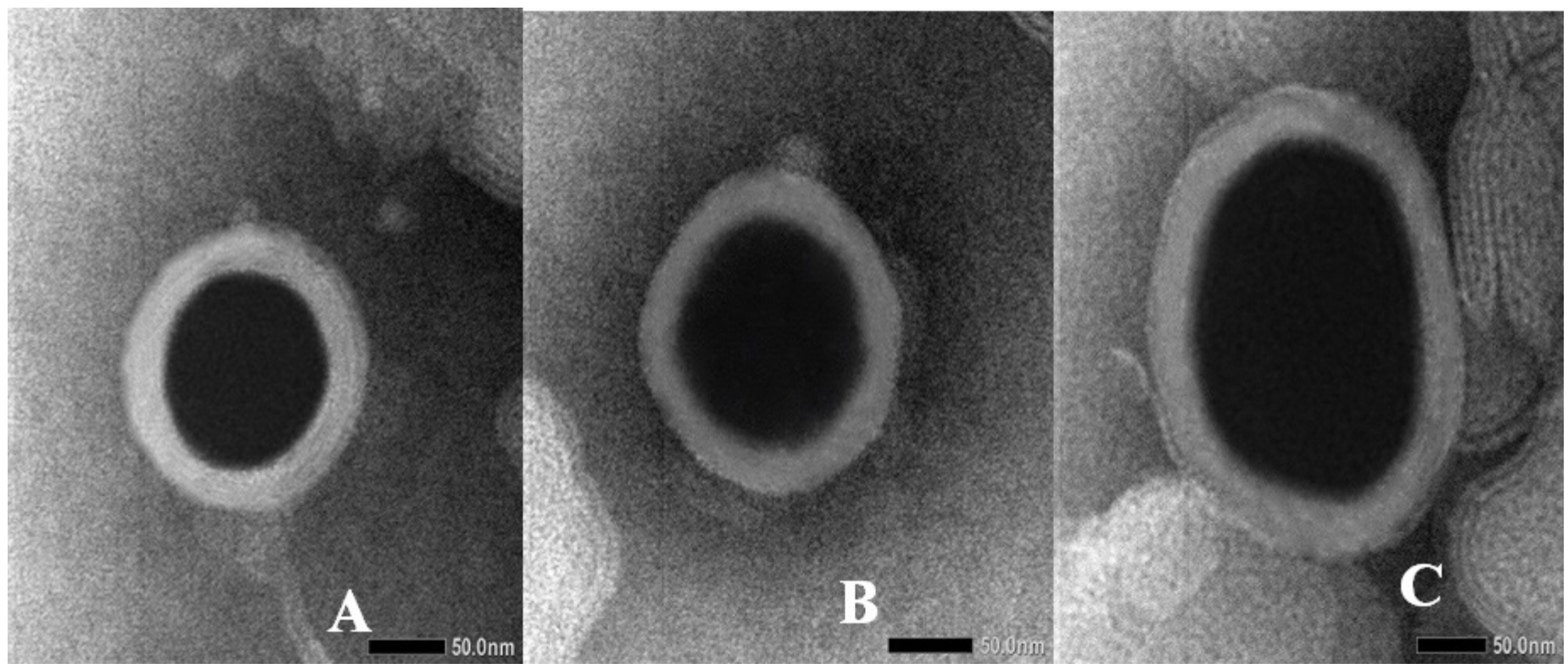

Figure 1: Morphology of vesicles at 80,0000 magnification. (A) F1, (B) F2 and (C) F3. 
Ramadon et al.: Transdermal Ethosomal Gel Containing Green Tea Leaves Extract

\begin{tabular}{cccccc}
\multicolumn{6}{l}{ Table 3: Summary of ethosomes characterization results } \\
\hline Sample & Morphology & Dv90 $(\mathrm{nm})$ & $\begin{array}{c}\text { Polydispersity } \\
\text { Index }\end{array}$ & $\begin{array}{c}\text { Zeta Potential } \\
(\mathrm{mV})\end{array}$ & $\begin{array}{c}\text { Entrapment Efficiency } \\
(\%)\end{array}$ \\
\hline F1 & Spherical shape & $129.00 \pm 0.00$ & $0.05 \pm 0.00$ & $-66.33 \pm 2.32$ & $54.39 \pm 0.03$ \\
F2 & Spherical shape & $155.33 \pm 2.08$ & $0.07 \pm 0.02$ & $-61.30 \pm 2.60$ & $39.98 \pm 0.16$ \\
F3 & Spherical shape & $232.67 \pm 2.52$ & $0.25 \pm 0.03$ & $-60.50 \pm 2.43$ & $33.32 \pm 0.29$ \\
\hline
\end{tabular}

Note: All values were represented as Mean \pm SEM ( $n=3$ ). (F1) Ethosome formula 1, (F2) Ethosome formula 2 and (F3) Ethosome formula 3

formulation, the smaller the particle size of the ethosome. It had a correlation to the ratio between the concentration of the active substance and ethanol. A high concentration of ethanol will reduce the thickness of the membrane vesicles, so the vesicles size will be smaller. ${ }^{9}$ The theory was proven by the results.

Another important physical property is the value of polydispersity index (PDI). PDI is the degree of heterogeneity of particles. The smaller or closer to zero of the PDI value, the less degree of heterogeneity of particle size. PDI with good value is $<0.7 .{ }^{18}$ The smaller the particle size, the smaller the value of IPD. F1 $(0.05 \pm 0.00), F 2(0.07 \pm 0.02)$ and F3 $(0.25 \pm 0.03)$.

In addition, zeta potential was also measured. A good value of zeta potential is greater than $+30 \mathrm{mV}$ or smaller than $-30 \mathrm{mV} .^{18}$ Zeta potential for each formula were F1 $(-66.33 \pm 2.32 \mathrm{mV}), \mathrm{F} 2(-61.30 \pm 2.60 \mathrm{mV})$ and F3 $(-60.50 \pm 2.43 \mathrm{mV})$. All formulas had zeta potential which is smaller than $-30 \mathrm{mV}$, so all three formulations have a good value of zeta potential. Zeta potential is affected by $\mathrm{pH}$, conductivity, and additives were charged. The negative charge produced from the ethanol in the system can prevent the aggregation of vesicles due to electrostatic repulsion and resistance force. The negative charge was caused by the vibration of sonication. ${ }^{16}$

\section{The Entrapment Efficiency}

The entrapment efficiency obtained for F1, F2, and F3 were $54.39 \pm 0.03 \%$, $39.98 \pm 0.16 \%$, and $33.32 \pm 0.29 \%$, respectively. Based on the percentage entrapment efficiency, the absolute value of the extract in ethosome respectively in $\mathrm{F} 1, \mathrm{~F} 2$, and $\mathrm{F} 3$ were $255.65 \pm 0.14 \mathrm{mg} ; 281.84 \pm 1.15 \mathrm{mg}$; and $313.20 \pm 2.76 \mathrm{mg}$. F1 was chosen to be incorporated into gel dosage form because there will be less remaining free extract that was not entrapped in the ethosome than F2 or F3. So, it would be more efficient. The entrapment efficiency will increase with the increase of the phospholipid concentration. ${ }^{19} \mathrm{~F} 1$ with the lowest concentration of EGCG had the best entrapment efficiency because phospholipids at a concentration of $4 \%$ can only entrap the active substances about 255.65 to $313.20 \mathrm{mg}$. Therefore, the addition of the active substance concentration in this study cannot significantly improve the efficiency of entrapment.

\section{Formulation of Selected Ethosome}

Formula that has a spherical morphology, a high percentage of entrapped drug, nano-sized $(<300 \mathrm{~nm})$, polydispersity index $<0.7$ and the zeta potential is more negative than -30 or more positive than $+30 \mathrm{mV}$ was chosen to be incorporated into gel dosage form. Based on the characterization, the selected formula was F1 because it had a spherical shape; $\mathrm{D}_{\text {mean }}$ particle size by volume was $90.53 \pm 0.32 \mathrm{~nm}$; polydispersity index of $0.05 \pm 0.00$; zeta potential $-62.6 \pm 5.05 \mathrm{mV}$; and the highest percentage of drug entrapped $(54.39 \pm 0.03 \%)$.

\section{Physicochemical Evaluation of Gel Dosage Forms}

EG color was pale orange (Pantone $1205 \mathrm{U}$ ), while the NEG was transparent orange (Pantone $143 \mathrm{U}){ }^{20}$ Both gels appeared homogeneous when smeared on a glass slide. The $\mathrm{pH}$ value of the EG and NEG at week
0 were 5.80 and 5.89 , respectively. The $\mathrm{pH}$ value suits the $\mathrm{pH}$ balance of the skin, i.e. 4.5-6.5.

Viscosity measurements at a speed of $20 \mathrm{rpm}$ for EG and NEG were $3100 \mathrm{cps}$ and 2300 cps, respectively. EG has higher viscosity due to the presence of phospholipid in formulations. Both gels were thixotropic with a plastic flow. Plastic flow curve does not pass through the point $(0.0)$ and has a yield value. Yield value is a straight line extrapolated from the curve straight to the axis of the shear stress. Preparations that have plastic flow will not flow when the shear stress does not pass the yield value. Thixotropic indicate that the decline curve on the left ascending curve which means that when a shear stress, the structure takes the time to get back to the original condition.

\section{Gel Stability}

Based on organoleptic and homogeneity observations of EG and NEG at low $\left(4 \pm 2{ }^{\circ} \mathrm{C}\right)$, room $\left(25 \pm 2{ }^{\circ} \mathrm{C}\right)$, and high $\left(40 \pm 2{ }^{\circ} \mathrm{C}\right)$ temperature, the organoleptic and homogeneity did not change. In observation of color, it did not change at the low-temperature storage. However, at room temperature and high temperature, there was discoloration on EG and NEG to a darker orange. The color changing was caused by the oxidation of EGCG in the gel. This oxidation process occurs due to the absence of additional antioxidants in the gel formulation.

Based on the measurements of $\mathrm{pH}$ for 8 weeks at different temperatures, it was obtained that the $\mathrm{pH}$ fluctuation was in the range of 5.40 to 6.13. The $\mathrm{pH}$ decreasing at room temperature and high temperature were caused by the oxidation of EGCG that increased the acidity. Additionally, the $\mathrm{pH}$ increase in storage at high temperatures caused the release of TEA from the gel matrix that increases the alkalinity. The changes were acceptable because the $\mathrm{pH}$ range is still at the acidity of the skin (4.5-6.5). The results of viscosity measurements at the speed of $20 \mathrm{rpm}$ on EG and NEG were $2800 \mathrm{cps}$ and $2100 \mathrm{cps}$, respectively. Based on the results, there was a decrease in the viscosity of the EG and NEG caused by the oxidation of EGCG, thus increase the acidity of the gels. These results were in line with the fall of the $\mathrm{pH}$ stability at room temperature. EG and NEG retained the plastic thixotropic flow properties.

\section{In vitro Penetration Test}

After the penetration test for $24 \mathrm{~h}$ with 13 points of sampling, it was obtained the cumulative amount of EGCG penetrated for EG was $1364.28 \pm 56.32 \mu \mathrm{g} / \mathrm{cm}^{2}$, while the NEG was $490.17 \pm 2.60 \mu \mathrm{g} / \mathrm{cm}^{2}$ (Figure 2) ( $\mathrm{p}<0.05)$. Cumulative percentage of penetrated EGCG for EG and NEG were $54.42 \pm 2.25 \%$ and $19.55 \pm 0.10 \%$, respectively. Based on these results, the EG had a greater amount of EGCG penetrated than the NEG. EGCG absorption through the skin in EG and NEG have a lag time of $1.71 \pm 0.05$ and $14.25 \pm 0.03 \mathrm{~h}$. The flux value that was generated from EG and NEG was $56.97 \pm 2.06 \mu \mathrm{g} \cdot \mathrm{cm}^{-2} \cdot \mathrm{h}^{-1}$ and $31.09 \pm 0.2 \mu \mathrm{g} \cdot \mathrm{cm}^{-2} \cdot \mathrm{h}^{-1}$. Based on these results it can be concluded that the EG has better flux value. The flux value indicates that the penetration rate of EGCG was faster from EG than NEG. The increased of EGCG penetrated that was contained in ethosome occur with a variety of mechanisms. The ethosome size was smaller than $300 \mathrm{~nm}$, that made the ethosome can pass through 


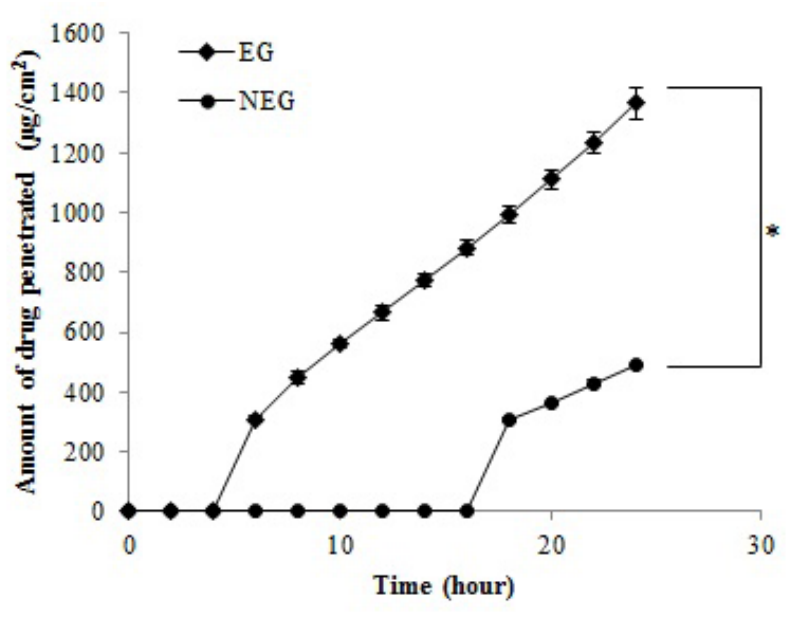

Figure 2: Cumulative of EGCG penetrated. All values were represented as Mean \pm SEM $(n=3) .\left({ }^{*}\right) p<0.05$ compared to control group.

the membrane skin to the deeper layers. ${ }^{16}$ The effects of ethanol and propylene glycol in the suspension as penetration enhancers will cause an interaction with the lipid molecules of the stratum corneum. It will increase the fluidity of the lipid bilayer. Then, this leads to the increase in permeability of the stratum corneum to the drug. ${ }^{21}$

The EGCG entrapped in ethosome, containing phospholipid (having the same structure with the lipid bilayer skin) and ethanol (causing the fluidity of vesicles), was another reason for increasing of EGCG penetrated. ${ }^{11}$ The vesicles that were formulated into a gel dosage form can be a controlled release delivery. ${ }^{22}$ The amount of EGCG penetrated from NEG was less due to the hydrophilicity of EGCG, making it difficult to penetrate through the skin. The additional of ethanol in NEG only helps the penetration of EGCG in small quantities. These results are in line with previous research, which was EGCG was not penetrated to the receptor medium and simply deposited in the skin. ${ }^{23}$ Another most important factor that can affect drug penetration is partition coefficient. ${ }^{24}$ When EGCG is entrapped in the vesicle, the coefficient partition of phospholipid is similar with lipid in the stratum corneum. Thus, penetration of EGCG from EG was higher than NEG.

\section{CONCLUSION}

It can be concluded that ethosomal gel can increase the penetration and stability of EGCG from green tea leaves extract.

\section{ACKNOWLEDGEMENT}

The authors are highly thankful to Universitas Indonesia who had given a financial support for this research, particularly for PITTA Research Grants 2016 No. 1823/UN2.R12/HKP.05.00/2016.

\section{CONFLICT OF INTEREST}

Authors declare that there is no conflict of interest.

\section{ABBREVIATION USED}

EGCG: Epigallocatechin gallate; MRP: Multidrug-resistance-associated protein; GIT: Gastrointestinal tract; UV: Ultra Violet; TEM: transmission electron microscope; \%EE: Entrapment efficiency; IC: Inhibitor concentration; PDI: Polydispersity index.

\section{REFERENCES}

1. Du G, Zhang Z, Wen X, Yu C, Calway T, Yuan C, et al. Epigallocatechin Gallate (EGCG) Is the Most Effective Cancer Chemopreventive Polyphenol in Green Tea. Nutrients. 2012;4(11):1679-91. https://doi.org/10.3390/nu4111679; PMid:23201840 PMCid:PMC3509513

2. Sharangi AB. Medicinal and therapeutic potentialities of tea (Camellia sinensis L.) - A review. Food Res Int. 2009;42(5-6):529-35. https://doi.org/10.1016/j. foodres.2009.01.007.

3. Patel AR, Velikov KP. Non-covalent interactions of green tea polyphenols: Source of novel colloidal structures. Nova Biomedical. 2013;151-66. PMCid:PMC3696132.

4. Legeay S, Rodier M, Fillon L, Faure S, Clere N. Epigallocatechin Gallate: A Review of Its Beneficial Properties to Prevent Metabolic Syndrome. Nutrients. 2015;7(7): 5443-68. https://doi.org/10.3390/nu7075230; PMid:26198245 PMCid:PMC4517007.

5. Hong J, Lambert JD, Lee SH, Sinko PJ, Yang CS. Involvement of multidrug resistance-associated proteins in regulating cellular levels of (-)-epigallocatechin3-gallate and its methyl metabolites. Biochem Bioph Res Co. 2003;310(1):222-7. https://doi.org/10.1016/j.bbrc.2003.09.007.

6. Sharma A, Saini S, Rana AC. Transdermal Drug Delivery System : A Review. Int J Res in Pharm Biomed Sci. 2013;4(1):286-92.

7. Prausnitz MR, Langer R. Transdermal drug delivery. Nat Biotechnol. 2009;26(11): 1261-8. https://doi.org/10.1038/nbt.1504;PMid:18997767PMCid:PMC2700785

8. Rakesh R, Anoop KR. Ethosomes For Transdermal And Topical Drug Delivery. Int J Pharm Pharm Sci. 2012;4(3):17-24.

9. Shelke S, Shahi S, Kale S, Patil V, Deshpande D. Ethosomes : A Novel Deformable Carrier. World J Pharm Sci. 2015;3(9):1830-9.

10. Verma P, Pathak K. Therapeutic and cosmeceutical potential of ethosomes: An overview. J Adv Pharm Technol Res. 2010;1(3):274. https://doi.org/10.4103/ 0110-5558.72415; PMid:22247858 PMCid:PMC3255417.

11. Notman R, Anwar J. Breaching the skin barrier - Insights from molecular simulation of model membranes. Adv Drug Delivery Rev. 2013;65(2):237-50. https://doi. org/10.1016/j.addr.2012.02.011; PMid:22414344.

12. Mitsui T. New Cosmetic Science. Amsterdam: Elsevier Science. 1998.

13. Gandjar IG, Rohman A. Kimia Farmasi Analisis. Yogyakarta: Pustaka Pelajar. 2007.

14. Phongpaichit S, Nikom S, Sakayaroj J, Towatana NH, RukachaisirikulV, Kirtikara K. Biological Activities of Extracts From Endophytic Fungi Isolated From Garcinia Plant. Immuno Med Mic. 2007;51(3):517-25. https://doi.org/10.1111/j.1574695X.2007.00331.x ; PMid:17888010.

15. Ahmed S, Ahmed I, Satar R, Ahmed S. In vitro assessment of pharmaceutical potential of ethosomes entrapped with terbinafine hydrochloride. J Adv Res. 2016;7(3):453-61. https://doi.org/10.1016/j.jare.2016.03.003 ; PMid:27222750 PMCid:PMC4856831.

16. Samnani A, Shahwal V, Bhowmick M, Joshi A, Dubey BK. Design and Evaluation of Ultradeformable Soft Elastic Nano Vesicle Ethosomes for Dermal Delivery. Int J Biomed Adv Res. 2012;03(02):111-7. https://doi.org/10.7439/ijbar.v3i2.232.

17. Verma P. Pathak K. Nanosized ethanolic vesicles loaded with econazole nitrate for the treatment of deep fungal infections through topical gel formulation. Nanomedicine : NBM. 2012;8(4):489-96. https://doi.org/10.1016/j.nano.2011.07.004 PMid:21839053.

18. Malvern Instruments. Dynamic Light Scattering Common Terms Defined. 2011;1-6.

19. Chaudhary H, Kohli K, Kumar V. Nano-transfersomes as a novel carrier for transdermal delivery. Int J Pharm. 2013;454(1):367-80. https://doi.org/10.1016/i. ijpharm.2013.07.031; PMid:23871739.

20. Pantone I. Simulations of Pantone Matching System Colors. New Jersey. 2004.

21. Bendas ER, Tadros MI. Enhanced transdermal delivery of salbutamol sulfate via ethosomes. AAPS PharmSciTech. 2007;8(4):E107. https://doi.org/10.1208/ pt0804107; PMid:18181528 PMCid:PMC2750693

22. Ahmed S, Ahmed I, Satar R, Ahmed S. In vitro assessment of pharmaceutical potential of ethosomes entrapped with terbinafine hydrochloride. J Adv Res. 2016;7(3):453-61. https://doi.org/10.1016/j.jare.2016.03.003; PMid:27222750 PMCid:PMC4856831.

23. Belo SE, Gaspar LR, Maia PMBG, Marty J. Skin Penetration of Epigallocatechin3-Gallate and Quercetin from Green Tea and Ginkgo biloba Extracts Vehiculated in Cosmetic Formulations. Skin Pharmacol Physiol. 2009;22(6):299-304. https:// doi.org/10.1159/000241299; PMid:19786823.

24. Anwar E, Ramadon D, Harmita H. Formulation and Evaluation of Gel and Emulgel of Chili Extract (Capsicum frutescens L.) as topical dosage forms. Int J Pharm Pharm Sci. 2014;6(Suppl 3):13-6. 